\title{
O VOO DA SERPENTE E AS ASAS DA BORBOLETA: SOBRE DOIS POEMAS DE ROBERTO CORREAA DOS SANTOS
}

\author{
THE SERPENT'S FLIGHT AND THE BUTTERFLY'S UINGS: \\ TWO POEMS BY ROBERTO CORREAA DOS SANTOS
}

\author{
Sérgio da Fonseca Amaral
}

Resumo: Ao abordar dois poemas de Roberto Corrêa dos Santos, neste artigo, tenho como propósito analisá-los a partir dos conflitos ali refletidos e pautados por uma construção poética que, ao evocar o sagrado, adentra campos sociais e políticos, operando contra as forças coercitivas e elevando o canto à vida, mesmo vislumbrando momentos limites entre os afetos - que geram vida, que provocam morte.

Palavras-chave: Roberto Corrêa dos Santos, Dois poemas, sagrado, político, Estado

Abstract: Approaching two poems by Roberto Corrêa dos Santos, in this article I have the purpose of analyze them from the conflicts reflected there, guided by a poetic construction that, evoking the sacred, enters the social and political fields, working against coercive forces and raising the song of life, even glimpsing limit moments between the affections - that generate life, that cause death.

Keywords: Roberto Corrêa dos Santos, Two poems, sacred, political, State

\footnotetext{
* Professor da Universidade Federal do Espírito Santo (UFES).
} 


\begin{abstract}
Desemprego, invenções pálidas, terras e saberes já com patentes, direitos zerados.

[...] ignorantes cada vez mais, só restará das artes o entretenimento - para endinheirar os que acatam a fome dos vampirismos. (Oswald: atos literários, $p$. 26).
\end{abstract}

oetas perambulavam de aldeia em aldeia, tocavam e cantavam seus cânticos tanto para transmitir passados acontecimentos humanos como para recordar os feitos perenes dos deuses; chegavam tanto para alegrar quanto para entristecer, assim eram os aedos, também os caraíbas ${ }^{1}$. Há ainda como encontrá-los nestes tempos midiáticos e de ciberespaço que fluem digitalmente? Depois do fim dos deuses e da apregoada morte da arte, de Deus, da história, das ideologias, do homem, do autor e de seus respectivos ressuscitamentos, haveria ainda os aedos e, se sim, que cantos poderiam sair de suas bocas? Que novas ainda seriam possíveis falar para um mundo disciplinado de norte a sul; de leste a oeste? E antes, haveria tais estirpes de poetas dispostos a serem os caraíbas em suas tribos, agora aglutinadas e concentradas na aldeia global do capitalismo?

Como se percebe, tais perguntas encerram duas proposições básicas que enlaçam as atividades poéticas e político-sociais.

Com o clima político nebuloso que se inicia nessa segunda década do século XXI, nos empurrando cada vez para o confinamento em nossos próprios lares e de vigilância sistemática sob o pretexto da segurança, a arte de modo geral e a poesia em particular em grande parte das vezes destilam tal situação em suas necessárias imersões no cotidiano das urbes infernais da velocidade e da virtualidade da vida. Há hodiernamente uma profusão de poetas de grande qualidade escrevendo e atuando de diversos modos, tais como Arnaldo Antunes, Eucanaã Ferraz, Antonio Cícero, Carlito Azevedo, Cláudia Roquete-Pinto, Douglas Diegues, Regis Bonvicino, lacy Anderson Freitas, Raimundo Carvalho, Paulo Henriques Britto, Glauco Mattoso, Casé Lontra Marques e tantos outros. Hoje, além da página do papel temos páginas outras que são exploradas de diferentes maneiras, de que espécie for. Por meio do computador tudo é possível para os

${ }^{1}$ Segundo Viveiros de Castro, caraíba seriam demiurgos, dotados de alta ciência xamânica (cf. CASTRO, 2011,p. 201). 
novos e novíssimos poetas, não abandonando, evidentemente, o papel. Entre as muitas alternativas, existem as performances, encenações como as do CEP 20.000, organizado por Guilherme Zarvos e Chacal, onde houve uma apresentação, com gravação de um CD, do poeta, ensaísta, professor e pensador Roberto Corrêa do Santos. Isso ainda no início dos anos 2000.

Mais emblemática dos tempos atuais foi a sua performance realizada, e gravada, na sede campestre do Instituto CEP 20.000 - Pensamento. A primeira coisa a ser notada nessas imagens/vozes/sonoplastia é a maneira como o seu desempenho reúne tanto o trabalho xamanístico quanto o legado dos Pais de Santo, inscrevendo o corpo à palavra, as marcas corpóreas ao signo oral e escrito. Lendo na folha a escrita do poema, a oralidade assume sua autonomia, imergindo os momentos da cena em todos os recursos possíveis para que o espírito da letra incorpore ao espectador/ouvinte/leitor.

Uma outra grafia se apresenta aí: a cinegrafia (considerando que se grava com tecnologia digital) funde-se ao som, decorrente da leitura, explora o ambiente para tornar-se imagem (com plantas e águas e céus e filtros na lente, enquadrando coloridos para os efeitos visuais). Junte-se a tudo isso a música, as batidas do atabaque e outros instrumentos (sintetizadores talvez) e teremos por fim montado um quadro completo do caraíba, do xamã aquém e além do moderno. A performance de Roberto Corrêa busca o primitivo: nos termos de Oswald de Andrade: o primitivo como ponto de chegada, não de partida. Primitivo esse expulso da cena da contemporaneidade das máquinas, robôs e inteligências artificiais.

A seguir transcrevo o poema, depurado da performance gravada.

\section{Invocação a Zarvos}

Esta é uma fala borrada, Zarvos

Uma fala tetragramétrica

E eu... se houvesse Eu

Eu seria o nome invisível porque eu sopro

Tome, Zarvos, dois goles de vida antes que nós dois faleçamos.

Ancilar! Sua alma neste instante, Zarvos, dorme... dorme... dorme...

Dorme sua alma como um cinto mágico

Após o feito, somente após o feito, consultem-se os oráculos

Quis nossa língua, meu amor 
Quis existir segundo o regimento das cores...

Atlantis!!!

Corpora. Álgebra. Algo desmonta.

Contudo não era o dia de falar mal das mães...?

E ólipos, sáurios, há uma sepultura para tudo!

Admo... adno... adnominação... curiano... báscula... amplex

O nome próprio seu possui setenta e duas letras.

A cobra cantou depois de lastimar três dias

E ao redor do morto todos, todos, todos, todos, todos, todos, todos, todos, todos, todos provisoriamente mortos

E não viver é a solução.

E não viver é a solução.

Fórmulas de primavera.

Alguém disse... sua outra parte Zarvos

Sua parte pulsante deu um salto.

Fórmulas de primavera!!!! Fórmulas de primavera!!!! Fórmulas de primavera!!!!

Fórmulas de primavera!

Não havia ninguém na casa.

E, por isso, canos, e pisos, e ladrilhos, e o mais comunicavam-se.

Não havia ninguém na casa.

E, por isso, canos, e pisos, e ladrilho, e o mais comunicavam-se.

Estalos e ventos e frases saídas do assoalho

Frases saídas do assoalho

Chegavam frases como o relâmpago

Mas você Zarvos, meu amor,

Disse ter a autoridade da sombra!

Zarvos! Zarvos!

Disse sim a ti, meu amor,

Desde que o critério fosse o peso.

E tu, amor, cuidarias dos últimos detalhes.

E quando eu chegar, amor,

Quando eu chegar para onde estou indo, amor,

Eu ligo, juro, eu ligo.

Zarvos, não tome a frase na flute.

Uma pestana voou até crescer entre dois azulejos. 
Corpo meu e teu inteiramente tingidos e sangrados.

Zaaaaaaaaaaaaaaaaaaaaaaaaaaaaaarvooooossssssssssssssss!

Mais verdadeiro não fora possível!

Estamos, Zarvos, indo às metabologias

Zaaaaaaaaaaaaaaaaaaaaaaaaaaaaaaarvooooosssssssssssssss! (SANTOS, 2015 )

Performance feita sentado, com um microfone numa mão e o papel noutra. Meias nas mãos, como luvas, colar de búzios. Interação com a música e com a sonoplastia. Leitura acompanhada de percussão de atabaques, jogo de câmera, luz, sombra e cores, capturando imagens do quintal da sede (um terreiro de umbanda virtual?) com suas árvores e plantas (bananeiras, coqueiros). Agitação dos búzios, os circundantes no pescoço do poeta, produzindo sons quando acariciados. O poema, ao invocar Zarvos, evoca o amor: o amor como criação, a criação do ato. O cunho sagrado e profético da poesia: os búzios, a "fala tetragramétrica", as quatro letras do impronunciável Nome-Deus da mitologia judaica, alusões às religiões afro. O paradoxo da fala do indizível, do não designável, a fissura no tabu do verbo: a multiplicidade introduzida no seio do único convocado a ser adorado pela tradição judaico-cristã. Desse modo, o painel, praticamente montado somente pela imagem do corpo do poeta, constitui não exatamente um sincretismo mas a convergência de quase todo o universo sagrado constitutivo dos Humanos; dos Humanos territorializados e mapeados como brasileiros.

Contudo, o dado religioso, o tom sacral do poema performado é atravessado pela existência profana e terrana em seus diversos nós que o constitui. Preenchendo o ambiente com frisson erótico, ao lado de cada evocação a Zarvos, junto à reverencia das setenta e duas letras de Seu nome, há os materiais de várias espécies de uma casa, as coisas entram em cena: falam, emanam sentidos, conversam com quem a adentra. Os assoalhos estalam (uma oração?), chamando a atenção para o mundo oculto que nos fabrica. Esse mundo - entre o sopro tetragramétrico e os cálculos algébricos das grandezas, fórmulas, mesmo que de primaveras - tem como origem o canto da serpente ("A cobra cantou depois de lastimar três dias"). Do canto, ao ovo, do ovo ao canto, o que gesta aí não costuma sagrar a vida. Seria por isso a duplicação, e a declamação em forma quase imperativa, do verso: "e não viver é a solução"?. Ou, ainda, o soturno do verso "há uma sepultura para tudo!". Assim, em "Invocação a Zarvos", há um enigmático fazer poético que tece junto a seus versos uma celebração da vida, da criação, 
do amor entrecortados por um alerta à alma que dorme em sono profundo, como um cinto mágico, contra os arautos tumulares. Os cintos, ainda que mágicos, são objetos de segurança, de prender, de envolver, de guardar, de garantir a posse, de cercar, de delimitar um corpo. Em tempos de guerra a qualquer manifestação política, "Invocação a Zarvos" canta com leveza e contundência a parte pulsante, conclamando ao salto e ao ato, antes que faleçamos.

Num pequeno livro publicado há alguns anos, também dedicado a Zarvos (um deles, pois a coleção de seis pequenos livros é dedicada a seis diferentes amizades), em um dos seus doze poemas há o seguinte quadro:

\author{
Uma \\ borboleta \\ perdida \\ bate \\ contra \\ paredes \\ (Morrer) \\ corações \\ rangem \\ mais \\ mais \\ e mais \\ gélidos
}

segues

firme

com

pés

sem

meias

sobre

laje

fria. (SANTOS, 2004, p. 4) 
Vislumbro nesses versos uma conexão com os supracitados da performance. A semelhança possivelmente seja encontrada menos no nome próprio declarado nas obras do que no tom sereno-perturbador dos poemas em suas alusões sinuosas e cruzadas, movimentando-se entre a sagração da vida, a potência do devir e a inevitabilidade política. A domesticação da vida - e a consequente humanização dos hominídeos, produzida por antropotecnias múltiplas, fabricadas, via de regra, pela arte política de Estados anti-sociais -, no mundo moderno, resulta em procedimentos opressivos recorrentes de forma de governo tirânica e/ou totalitária.

Os dois poemas de Roberto Corrêa em destaque, numa torção leve e vigorosa, sugestiva e densa, enredam os vários campos das circunstâncias do vivível/ invivível, incidindo sobre os limites que tiranizam a vida para celebrar a divindade que habita o hominídeo desde o seu processo de humanização: o além do homem é a fronteira a ser atravessada. Versos como "Uma/borboleta/perdida/ bate/contra/paredes" colocam em contraponto a maleabilidade, o movimento, a desenvoltura, a graça e a beleza, o incerto, a sinuosidade, o ir e vir sem rumo, o horizontal, o espaço aberto e, sobretudo, a liberdade, com a dureza, a fixidez, a reta, o objetivo, o espaço fechado, a barreira, o limite, a proteção, o divisor, o vertical, a clausura. Na mesma clave, versos como "Não havia ninguém na casa/E, por isso, canos, e pisos, e ladrilhos, e o mais comunicavam-se [...] Estalos e ventos e frases saídas do assoalho/Frases saídas do assoalho/Chegavam frases como o relâmpago" arranjam em simetria, ao mesmo tempo que fundem, relações paradoxais, mas orgânicas, divisando um conflito vindo do e indo ao infinito ("uma fala tetragramétrica"): a infindável, e incansável, luta morte/vida e seus antagônicos partidários, engalfinhando-se em todos os meios.

$\mathrm{O}$ segundo poema é montado sobre base três, o número perfeito. Três estrofes. Duas com seis versos cada, uma com nove, ou seja, uma estrofe e meia em relação às duas, que são anteriores. Nove é múltiplo de três e seis é o seu dobro. Isso não é para aqui invocar qualquer simbologia, mas apenas para mostrar a simetria estrutural do poema. De qualquer modo, o número três não deixa de guardar uma relação mística com a divindade e o sagrado, elementos caros à poesia de Roberto Corrêa. Logo, não deixa de ser relevante relacionar tal estrutura simétrica com os assuntos das três estrofes, que formam um "enredo" e se articulam: do abstrato ao concreto e ao abstrato novamente. Uma estrutura de eterno retorno. Um Ouroboros, um símbolo da eternidade com uma serpente 
devorando a própria cauda, e com isso retornamos à serpente... As duas primeiras sequências estróficas colocam em cena - a primeira metaforicamente, a segunda metonimicamente - situações próximas. A borboleta perdida tanto pode estar entre quatro paredes quanto em espaço aberto, dependendo de como entendermos o verbo perder no contexto, que pode significar ou estar prisioneira de alguém, sendo o seu um caso perdido; ou estar sem direção, que poderia ser um ato voluntário não fosse o fato de bater contra paredes, borboleteando. Uma outra possibilidade, que não entrarei em consideração, seria a conotação sexual. Em aceitando um ou outro ângulo de entendimento, saliente-se que um vai em direção oposta ao outro, pois, estando prisioneira, toda sua esperança ficou do lado de fora; já no espaço aberto, senhora de seu caminho, bater asas contra paredes é uma parte fundamental do exercício da liberdade. Em síntese, na primeira estrofe, com um único verbo e substantivo, cria-se uma tensão entre o coercitivo e a liberdade. Aqui, nesta estrofe, estamos no campo político.

A estrofe "corações/rangem/mais/mais/e mais/gélidos" encontramos talvez uma decomposição da primeira por se tratar agora de um caso mais concreto, adequando-se perfeitamente à metonímia burilada. O coração sendo uma metáfora dos sentimentos, no poema indica antes, por contiguidade, pessoas com sentimentos perdidos, ou paralisados. O verbo ranger, que se aplicaria a dobradiças ou a qualquer outro objeto que faça uma charneira com qualquer metal, cria um sintagma quase surreal ao articular-se com gélido. O que seria um ranger gélido? Mas ranger também pode ser dos dentes e um coração gélido praticamente está parado. Na Bíblia, há a suprema condenação lançada aos iníquos: "Então começareis a dizer: 'Comemos e bebemos contigo e ensinaste em nossas praças'. E responderá ele: 'Digo-vos: não sei de onde sois. Afastai-vos de mim todos vos que praticais a iniqüidade'. Ali haverá choro e ranger de dentes [...]" (LUCAS, 13:26-27-28).

Se para uma condenação na vida eterna haveria ranger de dentes, então os corações mais e mais gélidos rangeriam, porque enferrujados, até o seu colapso final. Contudo, tal colapso retorna, nesse caso ao campo metafórico do coração como o lugar dos sentimentos. Porém frieza e corações gélidos podem indicar, também, um mal sentimento: ou cálculo, ou indiferença. Sendo cálculo, indicaria a frieza do mundo dos negócios; indiferença, a massificação das gentes e a banalidade do mal que se apossaram da vida no mundo moderno. 
Já a terceira estrofe pareceria uma síntese dialética das duas anteriores. Ao contrário de bater contra paredes, o personagem-interlocutor segue firme; embora descalço, sem meias sobre a laje fria, encontrando uma frieza fora de si, mas longe do coração, é possível a Tu demonstrar força. A firmeza, o seguir em frente, portanto em linha reta, sobre um caminho adverso, conota que a personagem em meio aos vetores de coerção, da indiferença e da má consciência que cruza o mundo social, uma vez mais vai: não pode, mas tem de, precisa ir.

Como se vê, reatando com o performático poema mais acima estampado, presentificamos uma sagração, em que o profano e o sagrado fazem parte de uma mesma dimensão: o canto à vida, mas, sobretudo à liberdade da vida para ser vivida com as devida possibilidades em aberto.

Não deixa de ser curioso observar, nos dois poemas lidos, que as coisas, objetos, artefatos feitos pelas mãos humanas, Ihes são partes constitutivas, participativas (mas não antropomorfizadas) e, pontos ativos (empecilhos ou deflagradores), compondo a vida individual ou coletiva: ou seja, não são alheios ao mundo humano, mas dele tomam parte, criam condições e formas do viver. As coisas não deixam de presidir os espaços criados conjuntamente conosco - talvez sejamos nós, não elas, os verdadeiros objetos do consumo - ou para "azeitar" a existência ou para danificá-la ou destruí-la. Os dois modos de agir são enquadrados pelos poemas. Assim, a casa (o abrigo de onde se pode sair e voltar; partir e retornar) com seus aparelhos circulatórios e suas epidermes (canos, pisos, assoalhos e ladrilhos) preparam-se, a cada dia, quando está vazia, para o acolhimento. Frases como relâmpagos costumam sair de céus pesados: clarões perigosos e efêmeros mostram-se, e descarregam-se de casas nebulosas, o contraposto das sombras, silenciosas, expansivas e onipresentes. Nesses versos, pressentimos a interação entre habitantes e casa; objetos, fenômenos naturais e humanos (Não havia ninguém na casa/E, por isso, canos, e pisos, e ladrilho, e o mais comunicavam-se/Estalos e ventos e frases saídas do assoalho). Se no outro poema, vemos as paredes exercerem o papel de máquina de contenção em relação à borboleta, a laje fria molestando os pés de um andarilho ocasional, no "Invocação a Zarvos", poder-se-ia dizer que, se as paredes têm ouvidos, os pisos falariam pelos cotovelos, ao sinalizarem com suas ranhaduras, falhas, junções, poeiras, brilho, manchas, dureza, estética etc.

A estrutura de coisas e de gentes que compõe o mundo humano rege em grande parte a sociedade que apela às palavras que, como raios, atingem zonas 
interseccionais entre os eus ("se houvesse Eu") e os Outros. Entre as técnicas de domínio, de produção, de distribuição, de persuasão, de vigilância, de controle, de satisfação e de punição, em suma, da governantabilidade, segundo Foucault, aspira-se a possibilidade de que a vida (qualquer vida) viva. Penso em "Invocação a Zarvos" como uma generosa fala que afronta as contemporâneas palavras inóspitas, com suas decorrentes práticas cínicas e embalsamadas, que os agenciadores do capital propalam pelas redes massivas de comunicação. Uma vez mais a vida está propensa a derrapar na curva da história...

Pela lógica do Estado - para quem só existem dois tipos de pessoas: aquelas que mandam e aquelas que obedecem - a vida deve ser sempre refém da morte, física ou existencial ("há uma sepultura para tudo!"). Proteger, uma das apregoadas virtudes do Estado, transforma-se, sorrateira e obstinadamente, no contrário: caçar e punir. Com isso, os aduladores do, hoje, ciclópico Leviatã planetário aos poucos e a-celeradamente empurram o planeta para um deserto cinza e verde, mantendo na ordem os devidos hemisférios... Mas, ainda assim, uma vez mais, ainda não, Madadayo, a vida quer viver: ("Tome, Zarvos, dois goles de vida antes que nós dois faleçamos").

\section{Referências}

CASTRO, Eduardo Viveiros de. A inconstância da alma selvagem. São Paulo: Cosac Naify, 2011.

EVANGELHO SEGUNDO SÃO LUCAS. In: Bíblia sagrada. 11. ed. Tradução de Mateus Hoepers. Petrópolis: Vozes, 1985.

ROMANDINI, Fabián Ludueña. A comunidade dos espectros I: Antropotecnia. Tradução de Alexandre Nodari e Leonardo D’Ávila. Desterro, Florianópolis: Cultura e Barbárie, 2012.

SANTOS, Roberto Corrêa dos. Invocação a Zarvos. Organização: Guilherme Zarvos. Vídeo: Daniel Zarvos. Som e luz: Claudio Antunes. 18 jul 2015. Disponível em: https:// vimeo.com/134535482. Acesso em 30 jul 2015.

SANTOS, Roberto Corrêa dos. Série Comprimidos I: Zarvos. Rio de Janeiro: Otti Editor, 2004.

SANTOS, Roberto Corrêa dos. Oswald: atos literários. Belo Horizonte: Edições 2 Luas, 2000. 